\title{
Modelo e-Maturity (e-M): Sete Dimensões para Gestão da Tecnologia na Escola
}

\author{
Herik Zednik $^{1}$ \\ ${ }^{1}$ Centro de Ciência e Tecnologia (CCT)- Mestrado Profissional em Computação \\ Aplicada (MPCOMP) - Universidade Estadual do Ceará (UECE) \\ herik.zednik@ufrgs.br
}

\begin{abstract}
The objective of this study is to present the seven evaluative dimensions that make up the e-Maturity Model (e-M). The model is characterized as a tool for self-evaluation and monitoring of technopedagogical management. The tools allow an analysis of the level of maturity in relation to the strategic and effective use of ICT in improving educational outcomes and collaborates in the identification of the uses and appropriations of ICT in schools from a perspective of pedagogical practice. The questionnaire proposes seven basic dimensions for evaluation: Management and Leadership, Curricular Management, Management of Teaching and Learning Processes, Evaluation Management, Training Management, Resource Management and e-Safety Management.
\end{abstract}

Resumo. $O$ objetivo desse estudo é apresentar as sete dimensões avaliativas que compõem o Modelo e-Maturity (e-M). O modelo se caracteriza como uma ferramenta de autoavaliação e acompanhamento da gestão tecnopedagógica. $O$ instrumental permite uma análise do nível de maturidade em relação ao uso estratégico e eficaz das TIC na melhoria dos resultados educacionais e colabora na identificação dos usos e apropriações das TIC nas escolas, numa perspectiva da prática pedagógica. O questionário propõe sete dimensões básicas para a avaliação: Gestão e Liderança, Gestão Curricular, Gestão dos Processos de Ensino e Aprendizagem, Gestão Avaliativa, Gestão Formativa, Gestão dos Recursos e Gestão da e-Segurança.

\section{Introdução}

O conjunto de habilidades exigidas dos gestores escolares está cada vez maior e abrange várias áreas do conhecimento. Entre essas novas habilidades está a capacidade de estimular a maturidade eletrônica (e-Maturity) da escola. Nesse estudo, $e$-Maturity se traduz na "Evolução da capacidade e potencialidade da organização escolar de tomar decisões estratégicas e de utilizar de forma pedagógica e eficaz a tecnologia para melhorar os resultados educacionais" [Zednik, Tarouco, Klering, 2014].

Diante do novo cenário decorrente da revolução tecnológica, o papel do gestor escolar tem passado por profundas mudanças. A passagem da sociedade industrial para a era do conhecimento refletem mudanças principalmente na forma de pensar e atuar do gestor, exigindo que sejam mais qualificados e capazes de assumir responsabilidades, tomar decisões e saibam buscar soluções. Assim, “[...] a revolução tecnológica não 
VI Congresso Brasileiro de Informática na Educação (CBIE 2017)

Anais do XXIII Workshop de Informática na Escola (WIE 2017)

modifica somente as técnicas de produção e transmissão do conhecimento, mas as próprias estruturas e formas de organização" [PSE 2004, p.27].

Nesse novo contexto surgem as seguintes perguntas: Quais decisões devem ser tomadas para garantir um uso e uma gestão apropriada das TIC? Qual o papel do gestor no processo de maturidade da Gestão Tecnopedagógica da escola? Que ações podem ser desenvolvidas no espaço escolar que contribuam para o desenvolvimento da e-Maturity? Gestores e professores utilizam eficientemente o potencial das tecnologias para melhorar seus resultados educacionais?

Nessa nova era, pós-digital, é fundamental que o gestor compreenda que o trabalho pedagógico é o foco principal da escola e que a gestão eficiente da tecnologia pode potencializar o fazer pedagógico, e também se caracteriza como condição necessária para redimensionar o fazer administrativo, de modo a facilitar a introdução das mudanças na gestão, na prática docente e na concepção pedagógica da escola. Nesse contexto, o papel do gestor exige uma nova visão mais criativa, mais participativa, mais ética, mais democrática, mais proativa e tecnologicamente mais exigente.

A concepção metodológica deste estudo se baseia numa abordagem teóricodescritiva, e objetiva apresentar as sete dimensões avaliativas que compõem o Modelo $e$ Maturity (e-M). O modelo se configura como uma ferramenta de autoavaliação e acompanhamento da Gestão Tecnopedagógica e foi concebido com o propósito de ajudar as escolas de Educação Básica a potencializarem o uso pedagógico e eficiente da tecnologia. Objetiva oferecer dados que representem a maturidade atual da gestão da tecnologia numa perspectiva pedagógica, mas principalmente para apoiar e orientar o gestor no planejamento de ações necessárias de aprimoramento do uso pedagógico das TIC, bem como a ordem de precedência adequada destas ações.

Nesse sentido, o instrumental (e-M) colabora na identificação e acompanhamento dos usos e apropriações das TIC nas escolas, numa perspectiva da prática pedagógica e se consolida como instrumental de autoavaliação ${ }^{1}$, mas também de acompanhamento e controle, com o objetivo de, a partir de critérios avaliativos, gerar informações acerca da utilização das TIC na escola, que auxiliem os gestores e a comunidade escolar no planejamento e no direcionamento de ações estratégicas e eficazes, nas decisões e no estabelecimento de metas e introdução de ações pedagógicas e administrativas, visando à melhoria da qualidade educacional [Zednik et al 2013]

Para fundamentar a ideia evolucionária da maturidade eletrônica buscamos suporte na Teoria da Maturidade-Imaturidade, de Chris Argyris (1969); no Modelo de Maturidade de Capacidade de Software - CMM, proveniente da Engenharia de Software; e nas Perspectivas de Transformação de Paulo Roberto Motta [Motta 1999] e Klering (2014). O Modelo e-M teve como base os modelos e-Learning Maturity Model - eMM [Marshall e Mitchell 2004], Self Review Framework for ICT [NAACE. 2006] e o modelo $\mathrm{CM} 360^{\circ}$ [Franco; Santos e Terra 2009].

\section{Indicadores da $e$-Maturity}

$\mathrm{O}$ conceito geral de maturidade em educação baseia-se na ideia de amadurecimento como tendo crescido, desenvolvido em torno de um longo período de tempo, suficiente

\footnotetext{
${ }^{1}$ www.ematurity.com.br
} 
VI Congresso Brasileiro de Informática na Educação (CBIE 2017)

Anais do XXIII Workshop de Informática na Escola (WIE 2017)

para saber promover mudanças positivas e planejar ações e estratégias inovadoras que contribuam para um melhor desempenho educacional.

Nesse sentido, considerando o contexto educacional, compreende-se que não é suficiente introduzir a tecnologia nas escolas, faz-se necessário um contínuo e sistemático processo de amadurecimento da gestão tecnopedagógica, onde a escola evolua progressivamente sua capacidade de organização e de tomada de decisão estratégica, de forma a utilizar eficazmente a tecnologia para melhorar os índices educacionais. Em suma, gerir a mudança de cultura organizacional necessária para assegurar que o investimento em tecnologia seja aliado a práticas pedagógicas que conduzam à melhoria nos processos de ensino e aprendizagem.

A maturidade no contexto educacional mostra o quanto uma instituição progrediu no concernente à incorporação de ações planejadas como maneira de trabalho, refletindo sua eficácia. Assim, o objetivo principal de um modelo de maturidade é ajudar as escolas a avaliar, conhecer e compreender seu nível atual de desenvolvimento organizacional. Neste trabalho, especificamente, a maturidade está relacionada à Gestão das TIC, apontando uma direção para que as escolas possam evoluir na Gestão Tecnopedagógica, por meio do reconhecimento das competências necessárias. "Torna-se de vital importância para as organizações saber onde estão, pois, com esse conhecimento, saberão por onde começar e em que melhorar" [Bruno 2008, p. 34].

Compreende-se por tecnopedagogia o "[...] processo de maturidade que abrange a pedagogia em confluência com a tecnologia na formação do ser tecnológico" [Zednik 2015]. A tecnopedagogia busca combinar as linhas Gestão, Tecnologia e Pedagogia de forma que se tornem tão fluidas e talvez indistintas quanto possível nesse novo espaço escolar que se caracteriza pela desterritorialização, onde não existem barreiras de tempo e de espaço para que as pessoas interajam.

O conceito tem a intenção de se distanciar da pedagogia tecnicista, visto que nesta abordagem o elemento principal era a organização racional dos meios, ocupando o professor e o aluno posição secundária. Nessa nova abordagem, busca-se fazer referência a uma nova concepção de educação que satisfaça os critérios modernos, a capacidade sistemática e sinérgica de uma instituição escolar, o desenvolvimento da competência pedagógica para a adoção das TIC no ambiente educacional, bem como o letramento tecnológico com o pedagógico da equipe escolar. Ou seja, que as TIC verdadeiramente estejam inclusas na ação pedagógica da escola.

Com o objetivo de favorecer o acompanhamento e avaliação da e-Maturity das escolas de Educação Básica, esse estudo desenvolvido pela Universidade Federal do Rio Grande do Sul (UFRGS), através do Programa de Pós-graduação em Informática na Educação (PPGIE) em parceria com a Universidade de Salamanca, identificou 7 (sete) dimensões fundamentais para condução da gestão tecnopedagógica, representadas na Figura 1. 
VI Congresso Brasileiro de Informática na Educação (CBIE 2017)

Anais do XXIII Workshop de Informática na Escola (WIE 2017)

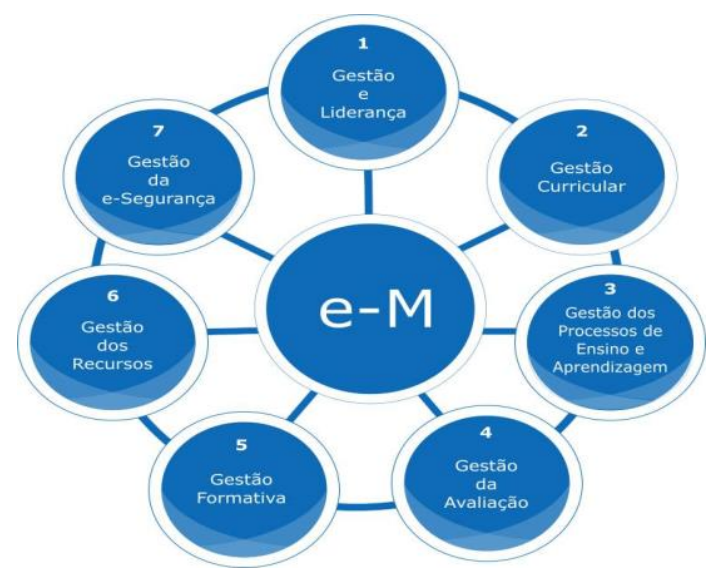

Figura 1: Sete dimensões da e-Maturity Fonte: próprio autor

As sete dimensões que compõem a estrutura geral do quadro de autoavaliação, proposto no Sistema e-M, estão conectadas e se influenciam mutualmente. As 6 (seis) primeiras dimensões (Gestão e Liderança; Planejamento Curricular; Gestão dos Processos de Ensino e Aprendizagem; Gestão da Avaliação; Gestão Formativa; Gestão dos Recursos) foram influenciadas pelo Self Review Framework for ICT (NAACE) ${ }^{2}$ (2006) e adequadas ao Modelo e-M. O sétimo elemento, e-segurança ou $e$-Safety, passou a compor o instrumental a partir da demanda atual onde se configura uma necessidade de preparar nossos jovens e equipe escolar para protegerem-se dos riscos associados ao uso das TIC e exposição à Internet, bem como o uso ético e consciente.

A ideia é que o instrumental de autoavaliação ofereça subsídios para que a gestão desenvolva uma prática pedagógica em confluência com os novos paradigmas da era pós-digital, direcionada para melhoria dos resultados educacionais. $\mathrm{O}$ instrumental traz um conjunto de questões que variam em uma escala do tipo Guttman, que vai de 1 a 5 (Figura 2). A escolha da escala de Guttman se justifica por esse modelo trabalhar melhor com questões hierárquicas e estruturadas, como os estágios evolucionários. As frases são organizadas de forma crescente, a formulação das frases, bem como a ordem pela qual são apresentadas, leva à ideia de acúmulo, de evolução de um estágio para outro.

\begin{tabular}{|c|c|c|c|}
\hline \multirow{6}{*}{$\begin{array}{l}0 \\
\mathbf{v} \\
\mathbf{u} \\
\mathbf{u}\end{array}$} & \multicolumn{2}{|r|}{ NÍVEIS } & PARÂMETROS DE AVALIAÇÃO \\
\hline & 1 & Leigo & $\begin{array}{l}\text { Não existe evidência de ações planejadas ou } \\
\text { desconhecem a questão. }\end{array}$ \\
\hline & 2 & Receptivo & $\begin{array}{l}\text { Há percepção de relevância da questão, mas não há } \\
\text { ação efetiva ou há iniciativas isoladas, não estruturadas } \\
\text { ou coordenadas. Os usuários estão numa posição } \\
\text { apenas receptiva da informação. }\end{array}$ \\
\hline & 3 & Proativo & $\begin{array}{l}\text { Há processo formal de planejamento para } \\
\text { desenvolvimento das principais atividades relacionadas } \\
\text { ao tema. }\end{array}$ \\
\hline & 4 & Ciberconfluente & $\begin{array}{l}\text { Planeja e apoia formalmente todas as atividades } \\
\text { relacionadas à questāo. }\end{array}$ \\
\hline & 5 & Maduro & $\begin{array}{l}\text { É referência no uso pedagógico das TIC. Cumpre com } \\
\text { todas as estratégias de utilização das TIC. É capaz de } \\
\text { criar, alterar e reorganizar as informações e transformá- } \\
\text { las em conhecimento. }\end{array}$ \\
\hline
\end{tabular}

Figura 2: Níveis X Parâmetros de avaliação Fonte: próprio autor

\footnotetext{
${ }^{2}$ National Association of Advisors for Computers in Education
} 
Os níveis de maturidade demandam uma gradação que indica quantitativamente, qual o estágio atual que a escola avaliada se encontra. Este indicador funciona da seguinte maneira: dentro de um critério estabelecido, cada aspecto abordado no questionário recebe do avaliador um nível de maturidade, com base na avaliação da realidade em que se encontra a escola em relação à gestão tecnopedagógica com base nos parâmetros de avaliação descritos na Figura 2 acima.

A definição dos níveis está diretamente ligada ao processo de democratização do saber, de como os sujeitos constroem novos espaços para a busca e o compartilhamento de informações, e, a partir dessas informações, constroem novos conhecimentos. A vivência de cada estágio inferior, portanto, ajuda a alcançar e consolidar o estágio posterior, rompendo com a ideia hierárquica dos níveis e contribuindo para a concepção de visão holística da capacidade da instituição.

\subsection{Gestão e Liderança}

O tema Gestão e Liderança conduz para uma análise da visão da escola em relação ao uso das TIC e vai ao encontro do novo perfil de gestor "[...] que ultrapassa a tarefa de gerenciamento e alcança a posição de liderança democrática da sua comunidade escolar [...] e se firma como substrato organizacional para o trabalho em cooperação" [Amaral 2006, p. 51].

Dessa forma, a Dimensão 1, Gestão e Liderança, requer do gestor estratégias de apropriação de informações que colaborem na construção de uma nova visão da escola em relação às TIC. Nesse sentido, é importante que o gestor estimule o desenvolvimento de uma cultura de uso estratégico, eficiente e pedagógico das TIC. Parte do princípio de que o gestor tenha consciência acerca do processo de mudança do uso da tecnologia e, que este, precisa ser entendido e gerenciado para poder conduzir a viabilização de uma aprendizagem ativa e colaborativa dos alunos dentro e fora da escola.

Nesse aspecto, busca-se o entendimento sobre a estratégia de uso das TIC como um elemento fundamental para melhoria da escola, que permita sua inovação e desenvolvimento. Evidencia também se o planejamento das TIC é criativo e flexível e se este define metas desafiadoras para ampliar o impacto das TIC para além da escola.

A Dimensão 1 também reflete acerca da eficácia orçamentária e procura mostrar os processos orçamentários no âmbito da estratégia de uso das TIC que garantam o desenvolvimento e renovação em longo prazo de todos os aspectos de sua implementação. Outro ponto importante é o entendimento da escola em relação ao impacto ambiental de sua estratégia de uso das TIC.

\subsection{Gestão do Currículo}

O gestor escolar da atualidade precisa ver o mundo em cinco "V's", Volume, Variedade, Velocidade, Veracidade e Valor. O que isso significa? Que o volume de informação é cada vez maior; sua diversidade é incalculável; a velocidade, segundo a Lei de Moore ${ }^{3}$, dobra a cada dois anos em relação à capacidade de processamento de dados; é essencial coletar dados verídicos, de acordo com a realidade; e saber estruturar as perguntas certas no princípio de todo processo de análise.

\footnotetext{
${ }^{3}$ A lei de Moore surgiu em 1965 através de um conceito estabelecido por Gordon Earl Moore. Tal lei dizia que o poder de processamento dos computadores dobraria a cada 18 meses.

Leia mais em: http://www.tecmundo.com.br/curiosidade/701-o-que-e-a-lei-de-moore-.htm\#ixzz2jyRCA2QA
} 
VI Congresso Brasileiro de Informática na Educação (CBIE 2017)

Anais do XXIII Workshop de Informática na Escola (WIE 2017)

Nesse sentido, as novas tecnologias trazem novos desafios ao currículo e muda o foco educacional "[...] da absorção do máximo possível de informação para a experiência de sobreviver em meio a tanta informação. Como consequência disso, uma das principais competências que se requer no mundo de hoje é a de filtrar e decifrar informação" [CETIC 2012, p. 46].

No mundo digital, o Gigabyte já é passado, a linguagem utilizada agora é Yottabyte, isso garante enorme capacidade de armazenamento de dados. Mas o que fazer com tão grande volume de informação? E a escola? Está preparada? Ou continua perpetuando o enorme descompasso denunciado por Libâneo [2000] na seguinte frase: "Somos professores do século XX, trabalhando conteúdos do século XIX e ensinando a alunos do século XXI".

O amadurecimento do processo de integração das TIC ao currículo permite mudanças significativas, como a não linearidade curricular (currículo rizomático), a possibilidade de combinar atividades on-line com atividades presenciais, viabiliza a introdução das TIC como parte integral das atividades da sala de aula, o que, consequentemente, "[...] envolve transformá-la em uma ferramenta para aperfeiçoar o conhecimento em uma determinada área de conhecimento ou em um contexto multidisciplinar" [Lucena 2006, p. 31].

Partindo desse princípio, a Dimensão Gestão do Currículo, busca compreender em que medida a escola sistematicamente mapeia o desenvolvimento das TIC no currículo. Direcionando para a necessidade de compreensão sobre a importância de o planejamento dispor de ações voltadas para o desenvolvimento da capacidade de uso eficaz e inovador das TIC para apoiar a aprendizagem e o ensino; garantir que os alunos sejam desafiados a fazer uso criativo e colaborativo das TIC, os professores levem em conta e baseiem-se nas experiências prévias dos alunos de uso das TIC.

\subsection{Gestão dos Processos Ensino e Aprendizagem}

Utilizar as TIC para a melhoria dos processos de ensino-aprendizagem e suas relações sociais e culturais, tem provocado "[...] mudanças profundas na educação presencial e a distância. Na presencial, desenraizam o conceito de ensino-aprendizagem localizado e temporal. Podemos aprender de vários lugares, ao mesmo tempo, on e off-line, juntos e separados" [Moran, 2006, p.58]. Na Educação a Distância supera-se a ideia de atividades solitárias e com alta exigência da autodisciplina e surgem novas ferramentas com grande poder de interação e colaboração.

Espera-se que a gestão eficiente do processo ensino-aprendizagem com integração das TIC, possibilite ambientes capazes de sediar excelentes espaços de aprendizagem, onde a socialização, o contexto e as interações permitam a construção significativa de novos conhecimentos, numa configuração dificilmente alcançada pelos espaços tradicionais de ensino e aprendizagem, com possibilidade real de desenvolvimento das competências comunicativa, interativa e reflexiva.

Nessa direção, a terceira dimensão aborda a Gestão dos Processos Ensino e Aprendizagem, com a finalidade de compreender $\mathrm{e}$ analisar o progresso da aprendizagem quando há mediação das TIC.

Implementar meios de melhor gerenciar esse aspecto significa também prover ações para desenvolver o domínio tecnopedagógico de forma que permita à escola modificar e inovar os processos de ensino e aprendizagem; construir ações efetivas sobre 
o uso pedagógico das TIC pelos alunos através de oportunidades de aprendizagem criativa e colaborativa; utilizar as TIC de forma inovadora para que os alunos continuem a ampliar seu aprendizado onde e quando quiserem; avaliar criticamente o uso das TIC na sua prática de ensino e seu impacto na aprendizagem dos alunos.

\subsection{Gestão da Avaliação das TIC}

Certamente um dos temas mais presentes no contexto escolar é a avaliação. Isto torna o debate acerca do tema bastante relevante, indispensável e atual. A Gestão Avaliativa, portanto, é o foco da Dimensão 4 (quatro), essa abordagem justifica-se pela necessidade de estimular os gestores escolares a conhecer e fazer bom uso das avaliações.

$\mathrm{O}$ ato de avaliar e saber utilizar seus resultados para que a escola cumpra sua função social e ofereça cada vez mais um ensino de qualidade é tarefa de todos os profissionais da educação para que os diferentes objetivos e possibilidades da avaliação da aprendizagem sejam alcançados. Portanto, esta dimensão compreende os seguintes aspectos sobre o processo avaliativo relacionado às TIC: avaliação eficaz dos progressos na capacidade de uso das TIC; incorporação dos recursos tecnológicos ao processo de avaliação do estudante; realização sistemática de autoavaliações e avaliação em pares ${ }^{4}$; integração da avaliação na aprendizagem dos alunos, em relação ao desenvolvimento de sua capacidade de uso pedagógico das TIC; definição e cumprimento metas desafiadoras para melhorar a capacidade de uso pedagógico das TIC; acompanhamento sistemático e rigoroso do progresso dos alunos; utilização da avaliação como instrumento para acompanhar o ensino e aprendizado e promover ações futuras.

\subsection{Gestão da Formação Docente para uso das TIC}

É crescente a preocupação com a formação dos professores no que concerne ao empoderamento das tecnologias digitais. Promover condições para que os professores incorporarem as TIC à prática pedagógica, de modo a favorecer a aprendizagem significativa dos alunos passa por uma formação de qualidade, que esteja conectada à realidade da sala de aula, que os capacite a fazer uso criativo e inovador das TIC e que tenha como ponto central o trabalho colaborativo.

Nesse sentido, a formação permanente para uso das TIC é imprescindível, e se estabelece na preparação de educadores para incorporá-las à sua prática pedagógica, de modo que os artefatos tecnológicos possam agregar valor às atividades escolares.

Segundo Mercado [1998, p. 16], “A formação de professores sinaliza para uma organização curricular inovadora que, ao ultrapassar a forma tradicional de organização curricular, estabelece novas relações entre a teoria e a prática". Nesse sentido, a formação deve oferecer condições para o trabalho coletivo e interdisciplinar, possibilitando o desenvolvimento de uma competência técnica e pedagógica que permita ao educador se situar criticamente e criativamente no novo espaço tecnológico.

Cabe ressaltar que a responsabilidade da escola passa também por oferecer atividades formativas e acesso à tecnologia para que a equipe escolar, em especial os professores, tenha melhores oportunidades de desenvolvimento de sua capacidade e potencialidade de trabalho.

\footnotetext{
${ }^{4}$ Avaliação em pares - avaliação entre pessoas que trabalham juntas e que estão em posição equivalentes entre si; pessoas no mesmo nível avaliam-se umas as outras.
} 
VI Congresso Brasileiro de Informática na Educação (CBIE 2017)

Anais do XXIII Workshop de Informática na Escola (WIE 2017)

\subsection{Gestão dos Recursos}

A grande quantidade de recursos disponíveis possibilita não apenas utilizá-los, mas também produzi-los e compartilhá-los. Isso exige, necessariamente, geri-los de forma competente e eficaz. Os modernos recursos de hardware e a ascensão da Web 3.0 possibilita aos educadores fazer uso desse enorme volume de recursos não apenas como consumidores e receptores de informação, mas também como criadores e socializadores. Além do enorme poder de colaboração e co-criação de conteúdos, a Web 3.0 permite a criação de sistemas de conhecimento coletivo, agentes inteligentes e a representação da informação de forma que os computadores sejam capazes de interpretá-la (web semântica).

Segundo Zednik et al (2015), “As mudanças inerentes na forma como a sociedade consome e produz recursos baseados na $W e b$ estão dirigindo um momento importante do ensino e da aprendizagem". Esse contexto exige, necessariamente, que esses recursos sejam geridos de forma competente e eficaz. Essa combinação entre gestão e tecnologia demanda a tomada de decisão acerca da ferramenta mais adequada para cada ação didática. Mas como se organizar em meio a esse emaranhado de tecnologias digitais que surgem todos os dias? Como escolher a ferramenta que melhor se adequa a estratégia didática planejada?

Com base nesse pressuposto, a Gestão dos Recursos busca identificar as seguintes situações: adequação dos recursos, incluindo hardware e software, para a aprendizagem digital e gestão escolar; acessibilidade aos recursos na hora e lugar planejado; condições e estratégias que supram os recursos adequados à eficácia das ações, sem perder a perspectiva humanista e política que distingue a escola das demais organizações; abordagens para o design inovador, adaptação ou reorganização de espaços que refletem totalmente a visão da escola para as TIC; variedade de recursos adequados, de alta qualidade que sejam suficientes para atender aos professores e as necessidades dos alunos; utilização dos recursos de forma inovadora e imaginativa; impacto significativo sobre a cultura e ética da escola; qualidade de conectividade; revisão e atualização regulares das demandas novas e crescentes; uso de ambientes de aprendizagem on-line para suporte de atividades inovadoras; capacitação do pessoal de apoio técnico para explorar e implementar soluções criativas e contribuírem para a formulação e desenvolvimento da estratégia da escola de uso das TIC; avaliação dos softwares empregados como meio de apoio ao trabalho docente e submetidos à exploração por parte dos alunos em processo de aprendizagem; os professores e coordenadores alcancem clareza das possibilidades e dos limites que cada recurso apresenta e de como eles podem ser inseridos na proposta pedagógica da escola.

\subsection{Gestão da e-Segurança}

A sétima dimensão, e-Segurança ou e-Safety, reflete a necessidade atual de preparar nossos jovens e equipe escolar para protegerem-se dos riscos associados ao uso das TIC e à exposição aos perigos da Internet como cybebullying, cybertrolling, e-privacy, pornografia virtual, cyber-pedofilia, plágios, roubo de informações e vírus informático.

A tecnologia precisa estar disponível da forma mais acessível possível ao estudante, porém sem descuidar da segurança. $\mathrm{O}$ desenvolvimento de uma comunidade mundial de educadores, estudantes e aprendizes permanentes, exige constante informação acerca da proteção e privacidade, para que possa atingir a plenitude de seu potencial a qualquer hora, em qualquer lugar e de qualquer equipamento. 
VI Congresso Brasileiro de Informática na Educação (CBIE 2017)

Anais do XXIII Workshop de Informática na Escola (WIE 2017)

Isso implica também orientar os alunos sobre netiqueta, pegada digital, violência cibernética, plágio entre outros. A dimensão Gestão da e-Segurança colabora com os seguintes aspectos:

- conscientização e realização de ações voltadas para a e-segurança; atenção da escola em identificar e responder aos novos desafios da segurança eletrônica;

-incentivo aos alunos, pais/responsáveis e a comunidade em geral para contribuir com uma política de $e$-Safety;

- compreensão da pegada digital e relacioná-la a uma estratégia de e-Safety;

-medidas para o conhecimento da legislação atual acerca de crimes virtuais.

É importante perceber que ao realizar qualquer atividade digital, deixamos rastros informacionais, ou seja, nossa pegada digital. Portanto, quando fazemos compras, telefonemas, buscas on-line, navegações, cliques, posts em mídias sociais (Facebook, Twitter etc.), comentários, compartilhamento de fotos e vídeos, registramos humor, preferências, compromissos, saúde, onde estamos, o que estamos fazendo etc., formam um dossiê sobre nós, com grande número de informações. Esses dados, quando analisados, personalizam as experiências, gostos e preferências das pessoas. "Esse fenômeno é denominado Quantified self (eu quantificado) e revela inúmeros aspectos sobre cada um de nós" [Gabriel 2013].

\section{Considerações Finais}

Finalizando, este estudo incide na apresentação das sete dimensões básicas que compõem o sistema e-Maturity (e-M). Procurando evidenciar as implicações diretas da gestão tecnopedagógica num contexto educacional marcado pela constante modernização das TIC. Os questionamentos propostos no sistema e-M colaboram para uma reflexão sistemática, cujas evidências encontradas a partir de uma prática reflexiva contribuem para o planejamento de ações coletivas que, por sua vez, contribuem para que a organização escolar possa tomar decisões estratégicas e passe a utilizar de forma mais efetiva e pedagógica a tecnologia para a melhoria dos resultados educacionais.

Nesta visão, o exercício de autoavaliação da e-Maturity mostra as valências, as fragilidades e as dificuldades da Gestão Tecnopedagógica e a capacidade de alinhamento para gerar o fortalecimento de toda a equipe e empoderamento das TIC no contexto escolar. Nesse contexto, as sete dimensões se estabelecem como instrumento de reflexão e de impulsão.

\section{Referências}

Alonso, M. (2003) “A gestão/administração educacional no contexto da atualidade". In: Gestão Educacional e Tecnologia. São Paulo: Avercamp,

Amaral, M. T. M. (2006) "Práticas educativas informatizadas". In: Liderança, gestão e tecnologias: para a melhoria da educação no Brasil. São Paulo: Pontifícia Universidade Católica de São Paulo - PUC-SP /Microsoft, 2006. p. 43-56.

Argyris, C. (1969) “A atitude da direção e seu impacto sobre os empregados". In Personalidade e organização: o conflito entre o sistema e o indivíduo (pp.121-157). Rio de Janeiro: Renes.

Bruno, G. D. (2008" "Maturidade em gestão do conhecimento: um estudo sobre as empresas do setor elétrico". Dissertação de mestrado profissional em administração. Rio de Janeiro: IBMEC. 
VI Congresso Brasileiro de Informática na Educação (CBIE 2017)

Anais do XXIII Workshop de Informática na Escola (WIE 2017)

CETIC 2012 (2011) "Pesquisa TIC Educação 2011: Pesquisa sobre o uso das tecnologias de informação e comunicação no Brasil". São Paulo: Comitê Gestor da Internet no Brasil, 2012. Disponível em < http://op.ceptro.br/cgi-bin/cetic/tic-educacao-2011.pdf $>$ Acesso em: 10/08/2013.

Franco, C. E.; Santos, M. L. B.; Terra, J. C. C. (2009) “Gestão de conteúdo 360: integrando negócios, design e tecnologia”. São Paulo: Saraiva.

Gabriel, Martha. (2013) "Educar: a (r)evolução digital na educação”. São Paulo: Saraiva.

Libâneo, J. C. (2000) "Adeus Professor, Adeus Professora? Novas exigências educacionais e profissão docente”. São Paulo0: Cortez, série Questões da nossa época, vol. 67, 2000. p. 104.

Lucena, M. (2006) “Integração das tecnologias na gestão escolar". In. Liderança gestão e tecnologias: para a melhoria da educação no Brasil. São Paulo: Pontifícia Universidade Católica de São Paulo - PUC-SP /Microsoft, 2006. p. 27-32.

Marshall, S. (2007) "Process Descriptions. e-Learning Maturity Model". New Zealand: University Teaching Development Centre, Victoria University of Wellington.

Mercado, L.P.L. (1998) "Formação docente e novas tecnologias". Universidade Federal de Alagoas. IV Congresso RIBIE, Brasília.

Moran, J. M. (2006) "Caminhar com segurança na mesma direção". In. Liderança gestão e tecnologias: para a melhoria da educação no Brasil. São Paulo: Pontifícia Universidade Católica de São Paulo - PUC-SP /Microsoft, 2006. p. 57-66.

Motta, P. R. (1999) "Transformação organizacional: a teoria e a prática de inovar". Rio de Janeiro: Qualitymark.

NAACE. (2006) "Self-review Framework (SRF)". Universidade de Nottingham. Acesso em: 03 de março de 2012. Disponível em: <http://www.naace.co.uk/ictmark/srf>.

Programa sua Escola a 2000 por Hora (PSE). (2004) "Educação para o desenvolvimento humano pela tecnologia digital”. São Paulo: Saraiva/Instituto Ayrton Senna (IAS).

Senge, P. M. (2006) “A quinta disciplina”. 21'. Edição - Rio de Janeiro: BestSeller.

Tarouco, L. M. R. et al. (2012) "Prova Brasil Multimídia: Um estudo sobre Interatividade". Rio de Janeiro: Anais do $23^{\circ}$ Simpósio Brasileiro de Informática na Educação.

Zednik, H.; Tarouco, L. M. R. e Klering, L. R. (2012) “e-Maturity: entrelaçando gestão, tecnologia e pedagogia". Porto Alegre: Revista Renote - Novas Tecnologias na Educação, V. 10 No 3, dezembro/2012.

Zednik et al. (2013) "Ciclo e-M: Avaliação Sistemática da Gestão Tecnopedagógica". II Congresso Brasileiro de Informática na Educação (CBIE 2013) Workshops (CBIE 2013). Campinas-SP.

Zednik, H., Tarouco, L.M.R., Klering, L. R. (2014) "Incorporação das TIC à gestão escolar e à prática pedagógica: indicadores para o desenvolvimento do e-Maturity". In: Formação a Distância para Gestores da Educação Básica: olhares sobre uma experiência no Rio Grande do Sul.1 ed. Porto Alegre: Evangraf, 2014, p. 21-51.

Zednik, H. (2015) "e-Maturity: Gestão da Tecnologia numa Perspectiva de Melhoria do Desempenho Pedagógico" Universidade Federal do Rio Grande do Sul, Centro de Estudos Interdisciplinares em Novas Tecnologias na Educação, Programa de Pós Graduação em Informática na Educação, Porto Alegre, 2015. 318 f. Tese de doutorado. 